\title{
Vitamin D Deficiency and Pseudofractures in Child-Bearing Egyptian Women: Successful Medical Treatment Helps to Avoid Fractures and Surgical Interference
}

\author{
Ghada M. El-Sagheer'1, Elwy Soliman², Ahlam M. Abdulla ${ }^{3}$, Mohamed Ali ${ }^{4}$ \\ ${ }^{1}$ Diabetes \& Endocrinology Unit, Internal Medicine Department, Minia University, El-Minia, Egypt \\ ${ }^{2}$ Internal Medicine Department, Minia University, El-Minia, Egypt \\ ${ }^{3}$ Biochemistry Department, Minia University, El-Minia, Egypt \\ ${ }^{4}$ Orthopedic and Trauma Surgery Department, Minia University, El-Minia, Egypt \\ Email: profmoali@yahoo.com
}

Received 28 June 2016; accepted 7 August 2016; published 10 August 2016

Copyright (C) 2016 by authors and Scientific Research Publishing Inc.

This work is licensed under the Creative Commons Attribution International License (CC BY). http://creativecommons.org/licenses/by/4.0/

c) (i) Open Access

\section{Abstract}

Background: Recent evidence for the effects of vitamin $D$ and recognition of the high prevalence of its deficiency has increased the interest in it. Vitamin D-sub nutrition may contribute to the risk of a wide range of disorders. Methods: The females in the child-bearing period attending the endocrinology and orthopedic out-patient clinics complaining of pain and/or tenderness at the groin were evaluated. Patients with chronic metabolic or skeletal illness, primary hyperparathyroidism, and patients receiving drugs that interfere with bone mineral metabolisms were excluded. One hundred accepted and consented to participation in the study. All the participants were subjected to full history taking, clinical evaluation, laboratory investigations including serum $\mathrm{Ca}, \mathrm{Ph}, \mathrm{PTH}$, ALP, TSH, F T4, F T3, Cortisol level, and 25(OH)D level. Plain X-ray was done for the regions of bony tenderness. The subjects were divided into 2 groups based on the presence or absence of pseudo-fractures (looser zones). They were treated and followed up till normalization of the laboratory parameters and healing of the looser zones. Results: The mean age for patients was $30.45 \pm$ 5.8 , their mean $25(\mathrm{OH})$ vitamin D level was $14.7 \pm 5.9 \mathrm{ng} / \mathrm{ml}$, the mean PTH was $195.7 \pm 162.6$, and looser zones were evident in the X-rays of 34 patients. The serum 25(OH)D showed significant negative correlations with veiling, parity, localized hip pain, and tenderness, ALP, PTH, but, a significant positive correlation with sun exposure, dairy products consumption, vitamin $D$ supplementation, and serum calcium levels. The independent factors associated with hypovitaminosis D were the lack of sun exposure, lack of vitamin D supplementation, and the presence of pseudofracture ( $p \leq 0.009,0.038$, and 0.001 respectively). No surgery was required in any of our patients. Conclusions: Vitamin D deficiency is common in our region. The main risk factors are decreased 
sun exposure, low dairy products consumption, and lack of vitamin D supplementation. Successful medical treatment may be helpful to satisfy the patient, avoid true fracture and further major surgical treatments.

\title{
Keywords
}

\author{
Hypovitaminosis D, Osteomalacia, Looser Zone
}

\section{Introduction}

Interest in vitamin D deficiency is increasing. It has been appreciated not only for its role in calcium homeostasis, and bone health [1] but also, for its role in many non-skeletal diseases and non-skin cancers [2]-[4]. Severe deficiency results in rickets and osteomalacia [5], while, less severe deficiency has been associated with numerous negative skeletal consequences, including secondary hyperparathyroidism, increased bone turnover, enhanced bone loss, and fracture risk [5] [6]. High prevalence of vitamin D deficiency was reported even in sunny climate areas of the world [7]. Because 1,25-dihydroxyvitamin D $\{1,25(\mathrm{OH}) 2 \mathrm{D}\}$ can be normal, high, or low in vitamin D deficiency [8], the most commonly used and most sensitive index for assessing vitamin D status is 25-hydroxy vitamin $\mathrm{D}\{25(\mathrm{OH}) \mathrm{D}\}$.

Many factors as age, sex, pubertal status, latitude, season, race, and ethnicity influence serum concentrations of 25(OH)D [9] [10]. In developing countries such as Egypt, data on clinical and subclinical vitamin D deficiency status are scarce. The aim of this study was to evaluate the successful medical treatment and its role in avoiding fractures and major surgical interference. We chose the females in the childbearing period as they represent the most vulnerable group for this problem.

\section{Material \& Methods}

After approval by the local institutional ethics committee at our hospital, we started this observational study from January to June 2015. The females in the child-bearing period attending the endocrinology and orthopedic out-patient clinics complaining of pain and/or tenderness at the groin especially if associated with generalized bone aches, muscle weakness, or bone minerals abnormalities were evaluated. The exclusion criteria included subjects with clinical features suggestive of any concurrent chronic illness including diabetes mellitus, primary hyperparathyroidism, other metabolic bone diseases; and intake of any drug that interferes with bone mineral metabolisms, such as glucocorticoids, anticonvulsants, and antituberculous drugs. From 135 patients met the inclusion criteria, only 100 accepted and consented for participation in the study.

History taking from the participants stressed on age, parity, no of children, history of veiling, sunlight exposure questionnaire ( $>30$ minutes/day is considered satisfactory), feeding habits especially dairy products, intake of drugs containing calcium and vitamin D. Clinical evaluation included weight and height measurement, calculation of the body/mass index BMI (weight $/ \mathrm{m}^{2}$ ), musculoskeletal examination. Laboratory investigations included complete blood picture (CBC), random blood sugar, serum calcium (Ca), phosphorus $(\mathrm{Ph})$, parathormone (PTH), alkaline phosphatase (ALP), thyroid stimulating hormone (TSH), Free T4, Free T3, Cortisol level, 25(OH)D level. Blood samples were collected from subjects in the fasting state without venostasis under basal conditions for estimation of total $\mathrm{Ca}, \mathrm{Ph}, \mathrm{ALP}, 25(\mathrm{OH}) \mathrm{D}$, and PTH. The serum was centrifuged at $4^{\circ} \mathrm{C}$ for 15 min at $1200 \times$ g and divided into 5 aliquots, which were refrigerated. Serum $\mathrm{Ca}, \mathrm{Ph}$, and ALP were estimated on the same day, and the remaining aliquots were stored at $-20^{\circ} \mathrm{C}$ until $25(\mathrm{OH}) \mathrm{D}$ and PTH were assessed by Chemolumencence immunoassay. According to the kit manufacturers, the normal laboratory range in adults for total serum $\mathrm{Ca}$ is $(8.10-10.04 \mathrm{mg} / \mathrm{dL})$, serum $\mathrm{Ph}$ is $(2.5-4.8 \mathrm{mg} / \mathrm{dL})$, serum ALP at $37^{\circ} \mathrm{C}$ is $100-275 \mathrm{IU} / \mathrm{L}$, 25(OH)D (reference range: 9.0 - $37.6 \mathrm{ng} / \mathrm{mL}$ ), and PTH (reference range: 13 - $66 \mathrm{pg} / \mathrm{mL}$ ). Plain x-ray was done for the regions of bony tenderness. MRI was done for some cases whenever X-rays were not satisfactory. The subjects were divided into 2 groups based on the presence or absence of pseudo-fractures (looser zones). The patients with looser zones were treated by a loading dose of vitamin D3 (200,000 Unit), followed by 50,000 Unit daily for one week, then 50,000 Unit weekly till normalization of the laboratory parameters, and then 1000 Unit 
daily. The patients without looser zones were treated using the same regimen, but, without the loading dose (20,0000 Unit). Every 4 weeks, the patients were followed up clinically and by laboratory investigation for Ca, ALP, PTH, and 25(OH)D for all patients plus plain X-rays for the patients with looser zones till complete improvement.

\section{Statistical Analysis}

Data was collected and included in a data based system and analyzed by statistical package of social sciences (SPSS Inc, Chicago, USA version 20) parametric data were expressed as mean \pm SDs. It was analyzed statistically using student t-test, while non parametric data were expressed as percentages and were analyzed using chi square. The pearson correlation coefficients were used to study the correlation between different parametric variables, spearman correlation coefficients were used to study the correlation with non-parameteric variables. Multiple linear regression analysis was done to estimate the independent variables associated with vitamin D deficiency, $\mathrm{P}$ values $<0.05$ were considered significant.

\section{Results}

A total of 100 female patients in the child-bearing period with a mean age of $30.45 \pm 5.8$ (range: 20 - 40) years participated in the study. Their mean BMI was $26.8 \pm 3.6$ (range: $21-35$ ) kg/m². Only 17 patients reported Sunlight exposure more than 30 minutes/day, while, 84 patients reported veiling. In relation to parity, 82 patients were multipara. Only 28 patients reported dairy products intake and 30 patients got Supplementation of vitamin $\mathrm{D}$ containing drugs. There was high incidence of fatigue and generalized body aches (63\% and $65 \%$ respectively). Localized hip pain was the main complaint in 49 patients and tenderness was found in 48 patients. Looser zones were evident in the X-rays of 34 patients. The mean Ca level was $7.14 \pm 0.64$ (range 6 - 8.2) mg/dL, the mean Ph level was $3.22 \pm 0.069$ (range 2 - 4.5) mg/dL, the mean ALP was $228 \pm 79$ (range 78 - 423) IU/L, the mean 25(OH)D level was $14.7 \pm 5.9$ (range 6 - 30) $\mathrm{ng} / \mathrm{ml}$, and the mean PTH was $195.7 \pm 162.6$ (range 33 - 712 ) (Table 1).

Comparing the two groups with and without pseudo-fractures, significant differences were found, as the patients with looser zones were multipara, had less vitamin supplementation, had more fatigue, generalized bone ache, proximal muscle weakness, localized hip pain and localized hip tenderness, lower serum Ca level, higher ALP level and PTH level (P value $\leq 0.000$ ) (Table 2).

Table 1. Demographic and base line characteristics of the patients group.

\begin{tabular}{cc}
\hline Variable & Patients (n = 100) \\
Age (Years) & $20-40(30.45 \pm 5.8)$ \\
BMI (kg/m²) & $21-35(26.8 \pm 3.6)$ \\
Sunlight exposure (Yes/No) & $17 \%-83 \%$ \\
Veiling (Yes/No) & $84 \%-16 \%$ \\
Parity (Yes/No) & $72 \%-28 \%$ \\
Dairy products intake (Yes/No) & $28 \%-72 \%$ \\
Supplementation (Yes/No) & $30 \%-70 \%$ \\
Fatigue (Yes/No) & $63 \%-37 \%$ \\
Generalized body aches (Yes/No) & $65 \%-35 \%$ \\
Localized hip pain (Yes/No) & $49 \%-51 \%$ \\
Localized hip tenderness (Yes/No) & $48 \%-52 \%$ \\
Looser zone in X-rays (Yes/No) & $34 \%-66 \%$ \\
Clinical improvement (<4wk/>4wk) & $62 \%-28 \%$ \\
Ca (mg/dL) & $6-8.2(7.14 \pm 0.64)$ \\
Ph (mg/dL) & $2-4.5(3.22 \pm 0.69)$ \\
ALP (IU/L) & $78-423(228 \pm 79)$ \\
25 OH vit D (ng/ml) & $6-30(14.7 \pm 5.9)$ \\
PTH (pg/ml) & $33-712(195.7 \pm 162.6)$
\end{tabular}

BMI: body mass index; Ca: calcium; Ph: phosphorus; ALP: alkaline phosphatase; PTH: parathormone. 
Table 2. Comparison of Clinical and biochemical data between the groups of patient with and without looser zones.

\begin{tabular}{cccc}
\hline Variable & Group1 (without pseudofracture) (66) & Group11 (with pseudofracture) (34) & P \\
\hline Age (Years) & $30 \pm 5.9$ & $31.1 \pm 5.6$ & 0.7 \\
BMI ((kg/m²) & $26.3 \pm 3.4$ & $27.5 \pm 3.5$ & 0.09 \\
Sun exposure (Yes/No) & $12 / 54$ & $4 / 30$ & 0.3 \\
Veiling (Yes/No) & $14 / 52$ & $5 / 29$ & 0.09 \\
Parity (Yes/No) & $23 / 43$ & $5 / 29$ & 0.02 \\
Dairy products intake (Yes/No) & $17 / 49$ & $5 / 29$ & 0.156 \\
Supplementation (Yes/No) & $25 / 41$ & $6 / 28$ & 0.01 \\
Proimal muscle weakness (Yes/No) & $27 / 39$ & $23 / 11$ & 0.01 \\
Fatigue (Yes/No) & $18 / 37$ & $32 / 13$ & 0.000 \\
Generalized body aches (Yes/No) & $24 / 42$ & $23 / 11$ & 0.433 \\
Localized hip pain (Yes/No) & $25 / 41$ & $25 / 9$ & 0.001 \\
Localized hip tenderness (Yes/No) & $23 / 43$ & $28 / 6$ & 0.000 \\
Ca (mg/dL) & $7.36 \pm 0.6$ & $6.85 \pm 0.57$ & 0.000 \\
Ph (mg/dL) & $3.3 \pm 0.7$ & $3.2 \pm 0.6$ & 0.632 \\
ALP (IU/L) & $203 \pm 81$ & $258 \pm 63.3$ & $11 \pm 4.35$ \\
25 OH vit D (ng/ml) & $17.7 \pm 5.3$ & $265.6 \pm 173.7$ & 0.000 \\
PTH (pg/ml & $140 \pm 130$ & 0.000 & 0.000 \\
\hline
\end{tabular}

Quantitative variables are expressed as mean \pm SD and compared using student $t$ test. Categorical variables are expressed as percentage and compared using Chi square. BMI: body mass index; Ca: calcium; Ph: phosphorus; ALP: alkaline phosphatase; PTH: parathormone. P value $\leq 0.05$ was considered significant.

Analysis of the association between the serum 25(OH)D level and the demographic, clinical, and laboratory variables revealed many significant correlations. The serum 25(OH)D showed significant negative correlations with veiling, parity, localized hip pain, and tenderness, ALP level, PTH level, but, a significant positive correlation with sun exposure, dairy products consumption, vitamin D supplementation, serum Ca level (Table 3).

Using multiple variable linear regression analysis, the independent factors associated with hypovitaminosis D were the lack of sun exposure, lack of vitamin $\mathrm{D}$ supplementation, and the presence of pseudofracture $(\mathrm{P} \leq 0.009$, 0.038, and 0.001 respectively) (Table 4).

All the clinical symptoms improved before 4 weeks in 62 patients (62\%), and after 4 weeks in the remaining 28 patients (28\%) (Table 1). This improvement was significantly correlated with the serum level of 25(OH)D, $(\mathrm{P} \leq 0.000)$ (Table 3). All the looser zones disappeared, meaning full mineralization of the poorly mineralized matrix. No surgery was required in any of our patients (Figure 1, Figure 2).

\section{Discussion}

Cutaneous production from sun exposure represents the main source of vitamin D [11], as naturally occurring dietary sources are limited, and supplementation or food fortification are inconsistent, or non-existent [12]. The amount and effectiveness of ultraviolet B radiation (UVB) from sunlight that reaches the skin are affected by many variables as time of day, season, latitude, altitude, clothing, veils, illiteracy, cultural habits, sunscreen use, pigmentation, and age [13]. The risk for vitamin D deficiency increases with little sun exposure, especially women who wear veils and decreased absorption of vitamin D from the intestine [14]. Vitamin D exerts wideranging effects, due, in part, to the fact that most tissues in the body contain receptors for 1,25(OH)2D [15]. Vitamin $\mathrm{D}$ is important in a number of physiologic processes, including calcium and phosphate absorption for the mineralization of the skeleton, innate and adaptive immunity, and homeostasis of a number of organs. Chronic vitamin D deficiency in adults results in osteoporosis, osteomalacia, muscle weakness, and increased risk of falls [16] [17].

Poor vitamin D intake and low blood levels of vitamin D metabolites are associated with increased incidence and severity of several autoimmune diseases involving the T-helper type 1 lymphocyte [18], including multiple 
Table 3. The association of serum 25(OH) vitamin D level with demographic, clinical and laboratory variables.

\begin{tabular}{ccc}
\hline Variable & & 25(OH)D \\
Age (years) & Spearman's r & 0.724 \\
BMI & -0.354 & 0.09 \\
Sun exposure & -1.690 & 0.000 \\
Veiling & 0.452 & 0.01 \\
Dairy consumption & -0.233 & 0.000 \\
Vitamin D supplementation & 0.367 & 0.003 \\
Parity & 0.379 & 0.001 \\
Fatigue & -0.340 & 0.019 \\
Proximal muscle weakness & -0.239 & 0.06 \\
Body ache & -0.188 & 0.04 \\
Localized hip pain & -0.204 & 0.001 \\
Localized hip tenderness & -0.327 & 0.001 \\
Ca & -0.293 & 0.000 \\
Ph & 4.217 & 0.623 \\
ALP & 0.494 & 0.000 \\
PTH & -3.802 & 0.000
\end{tabular}

BMI: body mass index; Ca: calcium; Ph: phosphorus; ALP: alkaline phosphatase; PTH: parathormone.

Table 4. Multiple linear regression analysis for factors associated with hypovitaminosis D $(\mathrm{n}=100)$.

\begin{tabular}{ccc}
\hline Variable & \multicolumn{2}{c}{ Odd ratio (CI 95\%) } \\
\hline Age (years) & $\mathrm{T}$ & 0.95 \\
BMI $\left(\mathrm{Kg} / \mathrm{m}^{2}\right)$ & -0.63 & 0.950 \\
Sun exposure & -1.063 & 0.009 \\
Veiling & 2.678 & 0.816 \\
Intake of dairy products & -0.234 & 0.525 \\
Vitamin D supplementation & -0.639 & 0.038 \\
Parity & -2.106 & 0.114 \\
Proximal weakness & 1.596 & 0.582 \\
Diffuse body aches & 0.553 & 0.915 \\
Localized hip pain & 0.108 & 0.204 \\
Localized hip tenderness & -1.281 & 0.188 \\
Pseudo-fracture & 1.327 & 0.001 \\
\hline
\end{tabular}

BMI: body mass index.

sclerosis [19], rheumatoid arthritis [20], type I diabetes [21], systemic lupus erythematosus [22] and psoriasis [23]. Lower levels of vitamin D, adjusted for body mass index, are also associated with increased risk of hypertension, myocardial infarction, and death as a result of cardiovascular disease [24]. Its deficiency in children causes rickets, and in adults, causes osteomalacia due to poor mineralization of the newly formed bone matrix (the osteoid) [25]. While bone deformities were associated with rickets, fractures and pseudofractures often were often associated with osteomalacia [26].

We agree with Henry and Bowyer [27] in that the combination of dietary deficiency of vitamin D, lack of 


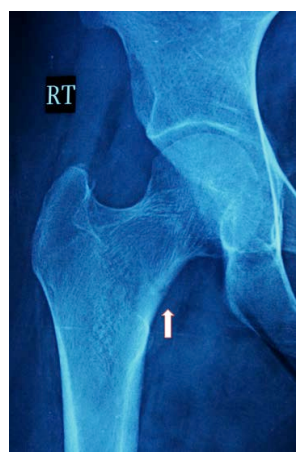

(a)
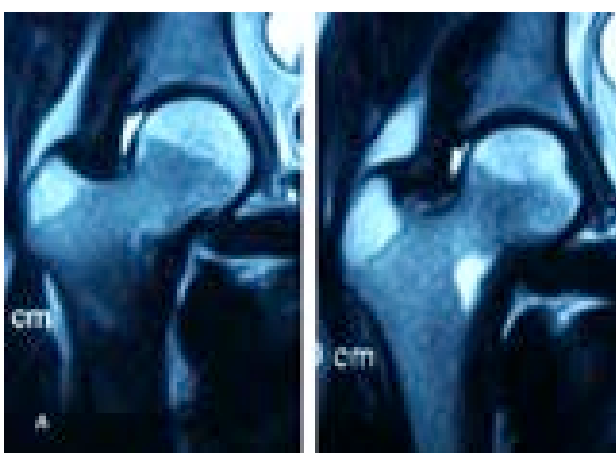

(b)
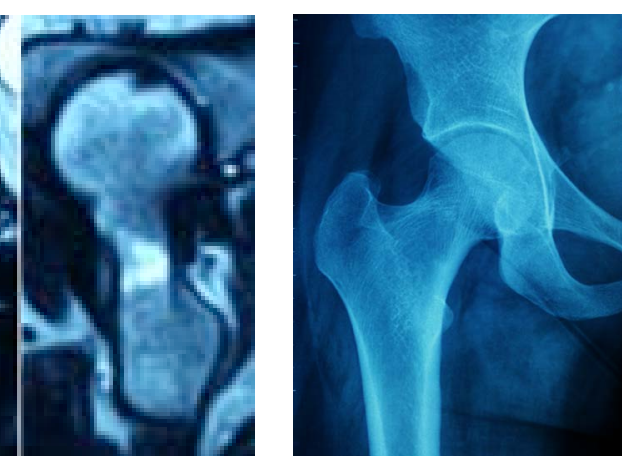

(c)

Figure 1. (a): Plain X-ray showing the looser zone in the neck of the right femur (white arrow). (b): MRI showing the looser zone. (c): Plain X-ray after healing of the looser zone

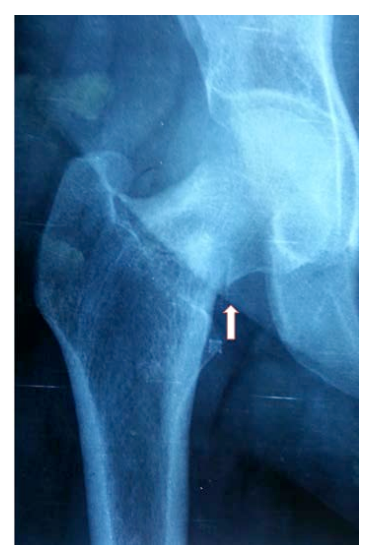

(a)

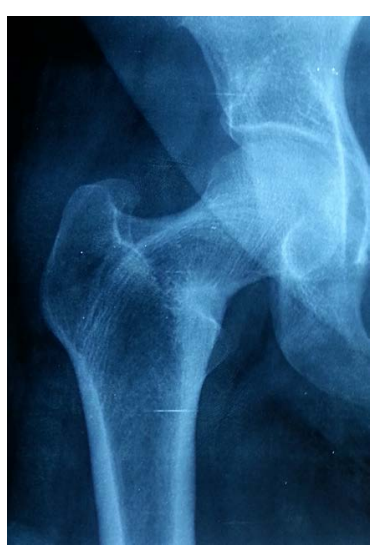

(b)

Figure 2. (a): Plain X-ray showing the looser zone in the neck of the right femur (white arrow). (b): Plain X-ray after healing of the looser zone.

exposure to sunlight, especially in women who wear traditional dress, limited intake of calcium and frequent pregnancies with subsequent lactation, severely affect the calcium metabolism, resulting in a negative calcium balance. Our study revealed significant negative correlations for serum 25(OH)D with veiling, parity, and a significant positive correlation for it with sun exposure, dairy products consumption, vitamin D supplementation, serum calcium levels. Also, multiple variable linear regression analysis showed that lack of sun exposure and lack of vitamin D supplementation represent two independent factors associated with hypovitaminosis D ( $\mathrm{P} \leq$ 0.009, 0.038 respectively).

Radiologically, osteomalacia may present with areas of no-or poorly-mineralised osteoid, recognised on radiographs as zones of increased radiolucency perpendicular to the long axis of the bone, named "Pseudofractures" or "Looser's zones" [28] [29]. Although Looser zones were reported in the literature as sporadic case reports [29] [30], but, this study represents the first, up to the best of our knowledge, to present this high number of cases with pseudofractures who represented $34 \%$ of patients. Also, the presence of pseudofractures represented an independent factor for hypovitaminosis D by Multiple variable linear regression analysis ( $\mathrm{P} \leq 001)$. A pseudofracture may be transferred to a true fracture, as a result of stress on the weak bone zone. No patient in our study got a true fracture as we agree with other authors [29]-[32], who reported that Pseudofractures often heal with calcium and vitamin D supplements if the diagnosis is made early. But, we add to them the high index of suspicion and adherence of the patients to the treatment protocol and instructions to avoid the potentially serious complications including true fractures. Also, the looser zones need to be investigated for other causes of osteomalacia as thyroid and parathyroid levels, renal functions, ultrasound examination of the neck.

Less severe vitamin D deficiency is quite common [33], often described as vitamin D insufficiency or inadequacy [34], causes stimulation of the parathyroid glands, which may lead to a high bone turnover, bone loss, 
pain, limitation of movements, and hip fractures [35]. Fractures may be predisposed by increased risk of falls or by repetitive stress on the demineralized bone. In our study, the mean PTH was $195.7 \pm 162.6 \mathrm{pg} / \mathrm{ml}$ and the serum 25(OH) vitamin D showed significant negative correlations with the PTH level.

We agree with Ohishi et al. [30] in that close follow up is important for many reasons. Of which, to avoid hypercalcemia or transformation to true fracture, monitor the early clinical and the later laboratory response to treatment, proper deciding when surgery become necessary before the incidence of complications, and the critical balance between the risk/benefit of early mobilization. High index of suspicion in vitamin D deficiency should be raised when you apparently healthy female adults complain from non-traumatic coxalgia especially if associated with generalized bone ache and muscle weakness. The importance of this is declared when we compare the cost benefit of successful medical treatment in face of surgical treatment for true fracture or further complications as hip joint arthroplasty in a young productive adult.

We agree with Lee and Lashari [29] in that not all pseudofractures require prophylactic fixation. Every case should be individually evaluated and managed by a team of an endocrinologist, an orthopedic surgeon, and a psychiatrist. A special care may be required for Obese, uncontrollable patients, who are susceptible to multiple falls or were heavy workers as they may be considered high-risk candidates for true fractures, and hence may be in greater need for prophylactic fixation.

Our study has several limitations including the limited number of patients, absence of a control group, the fact that we recruited participants in one setting, decreases generalizability of our findings, and absence of histological correlation with vitamin D deficiency.

\section{Conclusion}

Vitamin D deficiency is common at our region. The main risk factors are decreased sun exposure, low dairy products consumption, and lack of vitamin D supplementation. The possibility of vitamin D deficiency should be considered when young patients present with non-traumatic hip pain and generalized bone aches. Successful medical treatment may be helpful to satisfy the patient, avoid true fracture and further major surgical treatments, such as hip arthroplasty.

\section{References}

[1] Holick, M.F. (2007) Vitamin D deficiency. The New England Journal of Medicine, 357, 266-281. http://dx.doi.org/10.1056/NEJMra070553

[2] Peterlik, M. and Cross, H.S. (2005) Vitamin D and Calcium Deficits Predispose for Multiple Chronic Diseases. European Journal of Clinical Investigation, 35, 290-304. http://dx.doi.org/10.1111/j.1365-2362.2005.01487.X

[3] Holick, M.F. (2004) Sunlight and Vitamin D for Bone Health and Prevention of Autoimmune Diseases, Cancers, and Cardiovascular Disease. The American Journal of Clinical Nutrition, 80, S1678-S1688.

[4] Peterlik, M. and Cross, H.S. (2006) Dysfunction of the Vitamin D Endocrine System as Common Cause for Multiple Malignant and Other Chronic Diseases. Anticancer Research, 26, 2581-2588.

[5] Parfitt, A.M. (1998) Osteomalacia and Related Disorders. In: Avioli, L.V.and Krane, S.M., Eds., Metabolic Bone Disease, 3rd Edition, Academic Press, San Diego, CA, 345-386. http://dx.doi.org/10.1016/b978-012068700-8/50012-8

[6] Lips, P. (2001) Vitamin D Deficiency and Secondary Hyperparathyroidism in the Elderly: Consequences for Bone Loss and Fractures and Therapeutic Implications. Endocrine Reviews, 22, 477-501. http://dx.doi.org/10.1210/edrv.22.4.0437

[7] Marwaha, R.K., Tandon, N., Reddy, D.R., Aggarwal, R., Singh, R., Sawhney, R.C., Saluja, B., Ganie, M.A. and Singh, S. (2005) Vitamin D and Bone Mineral Density Status of Healthy Schoolchildren in Northern India. The American Journal of Clinical Nutrition, 82, 477-482.

[8] Hollis, B.W. (1996) Assessment of Vitamin D Nutritional and Hormonal Status: What to Measure and How to Do It. Calcified Tissue International, 58, 4-5. http://dx.doi.org/10.1007/BF02509538

[9] Adams, J.S. and Hollis, B.W. (2002) Vitamin D synthesis, Metabolism and Clinical Measurement. In: Coe, F.L. and Favus, M.J., Eds., Disorders of Bone and Mineral Metabolism, 2nd Edition, Lippincott Williams \& Wilkins, Philadelphia, PA, 157-174.

[10] Guillemant, J., Cabrol, S., Allemandou, A., Peres, G. and Guillemant, S. (1995) Vitamin D-Dependent Seasonal Variation of PTH in Growing Male Adolescents. Bone, 17, 513-516. http://dx.doi.org/10.1016/8756-3282(95)00401-7

[11] Holick, M.F. (1995) Environmental Factors That Influence the Cutaneous Production of Vitamin D. The American 
Journal of Clinical Nutrition, 61, 638S-645S.

[12] Glerup, H., Mikkelsen, K., Poulsen, L., Hass, E., Overbeck, S., Thomsen, J., Charles, P. and Eriksen, E.F. (2000) Commonly Recommended Daily Intake of Vitamin D Is Not Sufficient If Sunlight Exposure Is Limited. Journal of Internal Medicine, 247, 260-268. http://dx.doi.org/10.1046/j.1365-2796.2000.00595.x

[13] Khoja, S.O., Khan, J.A., Berry, J.L., Maimani, A.R., Woolf, A.D. and Lanham-New, S.A. (2006) Nutritional Influences on Bone in Saudi Arabian Women: Widespread Vitamin D Deficiency. 6th International Symposium on Nutritional Aspects of Osteoporosis, Lausanne, Switzerland, 4-6 May 2006.

[14] Kennel, K.A., Drake, M.T. and Hurley, D.L. (2010) Vitamin D Deficiency in Adults: When to Test and How to Treat. Mayo Clinic Proceedings, 85, 752-7; quiz 757-8. http://dx.doi.org/10.4065/mcp.2010.0138

[15] Pérez-López, F.R. (2007) Vitamin D and Its Implications for Musculoskeletal Health in Women: An Update. Maturitas, 58, 117-137. http://dx.doi.org/10.1016/j.maturitas.2007.05.002

[16] Lips, P. (1996) Vitamin D Deficiency and Osteoporosis: The Role of Vitamin D Deficiency and Treatment with Vitamin D and Analogues in the Prevention of Osteoporosis-Related Fractures. European Journal of Clinical Investigation, 26, 436-442. http://dx.doi.org/10.1046/j.1365-2362.1996.176290.x

[17] Bischoff-Ferrari, H.A., Zhang, Y., Kiel, D.P. and Felson, D.T. (2005) Positive Association between Serum 25-Hydroxyvitamin D Level and Bone Density in Osteoarthritis. Arthritis \& Rheumatology, 53, 821-826. http://dx.doi.org/10.1002/art.21601

[18] Adorini, L. and Penna, G. (2008) Control of Autoimmune Diseases by the Vitamin D Endocrine System. Nature Clinical Practice Rheumatology, 4, 404-412. http://dx.doi.org/10.1038/ncprheum0855

[19] Munger, K.L., Levin, L.I., Hollis, B.W., Howard, N.S. and Ascherio, A. (2006) Serum 25-Hydroxyvitamin D Levels and Risk of Multiple Sclerosis. JAMA, 296, 2832-2838. http://dx.doi.org/10.1001/jama.296.23.2832

[20] Patel, S., Farragher, T., Berry, J., Bunn, D., Silman, A. and Symmons, D. (2007) Association between Serum Vitamin D Metabolite Levels and Disease Activity in Patients with Early Inflammatory Polyarthritis. Arthritis \& Rheumatology, 56, 2143-2149. http://dx.doi.org/10.1002/art.22722

[21] Mohr, S.B., Garland, C.F., Gorham, E.D. and Garland, F.C. (2008) The Association between Ultraviolet B Irradiance, Vitamin D Status and Incidence Rates of Type 1 Diabetes in 51 Regions Worldwide. Diabetologia, 51, 1391-1398. http://dx.doi.org/10.1007/s00125-008-1061-5

[22] Wu, P.W., Rhew, E.Y., Dyer, A.R., Dunlop, D., Langman, C., Sutton-Tyrrell, K., McPherson, D., Edmundowicz, D., Kondos, G. and Ramsey-Goldman, R. (2009) 25-Hydroxyvitamin D and Cardiovascular Risk Factors in Women with Systemic Lupus Erythematosus. Arthritis \& Rheumatology, 61, 1387-1395. http://dx.doi.org/10.1002/art.24785

[23] Tanghetti, E.A. (2009) The Role of Topical Vitamin D Modulators in Psoriasis Therapy. Journal of Drugs in Dermatology, 8, s4-s8.

[24] Kendrick, J., Targher, G., Smits, G. and Chonchol, M. (2009) 25-Hydroxyvitamin D Deficiency Is Independently Associated with Cardiovascular Disease in the Third National Health and Nutrition Examination Survey. Atherosclerosis, 205, 255-260. http://dx.doi.org/10.1016/j.atherosclerosis.2008.10.033

[25] Frame, B. and Parfitt, A.M. (1978) Osteomalacia, Current Concepts. Annals of Internal Medicine, 89, 966-982. http://dx.doi.org/10.7326/0003-4819-89-6-966

[26] Chalmers, J., Barclay, A., Davison, A.M., Macleod, D.A.D. and Williams, D.A. (1969) Quantitative Measurements of Osteoid in Health and Disease. Clinical Orthopaedics \& Related Research, 63, 196-209. http://dx.doi.org/10.1097/00003086-196903000-00022

[27] Henry, A. and Bowyer, L. (2003) Fracture of the Neck of Femur and Osteomalacia in Pregnancy. BJOG, 110, $329-330$. http://dx.doi.org/10.1046/j.1471-0528.2003.01142.x

[28] Baburaj, K. and Reid, D.M. (2004) Osteomalacia. Surgery, 22, 20-21. http://dx.doi.org/10.1383/surg.22.1.20.27042

[29] Lee, C. and Lashari, S. (2007) Pseudofracture of the Neck of Femur Secondary to Osteomalacia. The Journal of Bone \& Joint Surgery, 89-B, 956-958. http://dx.doi.org/10.1302/0301-620X.89B7.18425

[30] Ohishi, H., Nakamura, Y., Kishiya, M. and Toh, S. (2013) Spontaneous Femoral Neck Fracture Associated with a Low Serum Level of Vitamin D. Journal of Orthopaedic Science, 18, 496-499. http://dx.doi.org/10.1007/s00776-011-0171-y

[31] Faraj, A. (2003) Bilateral Simultaneous Combined Intra- and Extracapsular Femoral Neck Fracture Secondary to Nutritional Osteomalacia: A Case Report. Acta Orthopcedica Belgica, 69, 201-203.

[32] El-Desouki, M.I., Othman, S.M. and Fouda, M.A. (2004) Bone Mineral Density and Bone Scintigraphy in Adult Saudi Female Patients with Osteomalacia. Saudi Medical Journal, 25, 355-358.

[33] Chapuy, M.C., Preziosi, P., Maamer, M., Arnaud, S., Galan, P., Hercberg, S. and Meunier, P.J. (1997) Prevalence of 
Vitamin D Insufficiency in an Adult Normal Population. Osteoporosis International, 7, 439-443. http://dx.doi.org/10.1007/s001980050030

[34] Brickley, M., Mays, S. and Ives, R. (2005) Skeletal Manifestation of Vitamin D Deficiency Osteomalacia in Documented Historical Collections. International Journal of Osteoarchaeology, 15, 389-403. http://dx.doi.org/10.1002/oa.794

[35] Parfitt, A.M., Gallagher, J.C., Heaney, R.P., Johnston, C.C., Neer, R. and Whedon, C.G. (1982) Vitamin D and Bone Health in the Elderly. The American Journal of Clinical Nutrition, 36, 1014-1031.

\section{Submit or recommend next manuscript to SCIRP and we will provide best service for you:}

Accepting pre-submission inquiries through Email, Facebook, LinkedIn, Twitter, etc. A wide selection of journals (inclusive of 9 subjects, more than 200 journals)

Providing 24-hour high-quality service

User-friendly online submission system

Fair and swift peer-review system

Efficient typesetting and proofreading procedure

Display of the result of downloads and visits, as well as the number of cited articles

Maximum dissemination of your research work

Submit your manuscript at: http://papersubmission.scirp.org/ 